\title{
Protection Against Oxidative Stress-Induced Neurodegeneration by a Modulator for DJ-1, the Wild-Type of Familial Parkinson's Disease-Linked PARK7
}

Takashi Yanagida ${ }^{1}$, Yoshihisa Kitamura ${ }^{1, * a}$, Koichiro Yamane ${ }^{1}$, Kazunori Takahashi ${ }^{2}$, Kazuyuki Takata $^{1}$, Daijiro Yanagisawa ${ }^{1}$, Hiroyuki Yasui ${ }^{3}$, Takashi Taniguchi ${ }^{1}$, Takahiro Taira ${ }^{4}$, Toshio Honda ${ }^{2}$, and Hiroyoshi Ariga ${ }^{5, * b}$

\author{
${ }^{I}$ Department of Neurobiology, ${ }^{3}$ Department of Analytical and Bioinorganic Chemistry, Kyoto Pharmaceutical University, \\ Kyoto 607-8414, Japan \\ ${ }^{2}$ Faculty of Pharmaceutical Sciences, Hoshi University, Tokyo 142-8501, Japan \\ ${ }^{4}$ Department of Molecular Cell Biology, Interdisciplinary Graduate School of Medicine and Engineering, \\ University of Yamanashi, Chuo 409-3898, Japan \\ ${ }^{5}$ Department of Molecular Biology, Graduate School of Pharmaceutical Sciences, Hokkaido University, \\ Sapporo 060-0812, Japan
}

Received December 1, 2008; Accepted January 9, 2009

\begin{abstract}
Although a loss-of-function type mutation was identified in familial Parkinson's disease PARK7, the wild-type of DJ-1 is known to act as an oxidative stress sensor in neuronal cells. Recently, we found a DJ-1 modulator UCP0054278 by in silico virtual screening. In this study, we determined the neuroprotective effects of UCP0054278 against focal ischemia-induced neurodegeneration in rats. Hydrogen peroxide-induced cell death and the production of reactive oxygen species were significantly inhibited by UCP0054278 in normal SH-SY5Y cells, but not in DJ-1-knockdown cells. These results suggest that UCP0054278 interacts with endogenous DJ-1 and then exhibits antioxidant and neuroprotective responses.
\end{abstract}

Keywords: DJ-1 modulator, anti-oxidative effect, neuroprotection

DJ-1 was first discovered as a novel oncogene product (1) and was later identified as a causative gene of familial Parkinson's disease (PD), PARK7 (2). Although gene mutations in DJ-1 (PARK7) cause loss-of-function, the wild-type DJ-1 is known to play a key role in antioxidant and neuroprotection in neuronal cells $(3-6)$. The wild-type DJ-1 in human and rat has three cysteine residues at amino acid numbers 46, 53, and 106 (C46, $\mathrm{C} 53$, and $\mathrm{C} 106$, respectively) (7). A cysteine residue is oxidized from a reduced form (-SH) to undergo sulphenation $(-\mathrm{SOH})$, sulphination $\left(-\mathrm{SO}_{2} \mathrm{H}\right)$, and sulphonation $\left(-\mathrm{SO}_{3} \mathrm{H}\right)$, in order of oxidative development. Among these three cysteine residues, $\mathrm{C} 106$ is the most sensitive to oxidative stress (7). Recently, we used the

\footnotetext{
*These contributors both served as senior authors.

Corresponding authors. ${ }^{* a}$ yo-kita@mb.kyoto-phu.ac.jp

*b hiro@pharm.hokudai.ac.jp

Published online in J-STAGE on March 11, 2009 (in advance) doi: $10.1254 /$ jphs.08323SC
}

X-ray crystal structure of oxidized DJ-1 at C106 with the $\mathrm{SO}_{2} \mathrm{H}$ form and the three-dimensional coordinate data of about 30,000 chemical compounds in the University Compound Project (UCP) at the Foundation for Education of Science and Technology and performed virtual screening (in silico) to search for DJ-1-binding modulators. Among the DJ-1 modulators identified in silico, 2-[3-(benzyloxy)-4-methoxyphenyl]- $N$-[2-(7-methoxy1,3-benzodioxol-5-yl)ethyl]acetamide (UCP0054278, Fig. 1A) has the highest binding constant (docking score) toward the pocket of the $\mathrm{SO}_{2} \mathrm{H}$-oxidized $\mathrm{C} 106$ region (8). In this study, we examined the effects of UCP0054278 on focal ischemia/reperfusion-induced oxidative brain damage in an in vivo rat model and on reactive oxygen species (ROS)-mediated cell death in normal and DJ-1-knockdown SH-SY5Y cells in an in vitro culture model.

Male Wistar rats (SLC, Shizuoka), weighing approximately 300 g, were used. Under deep anesthesia (sodium 


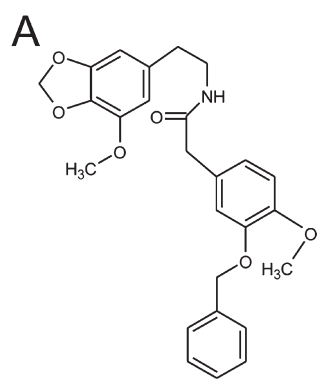

UCP0054278
B
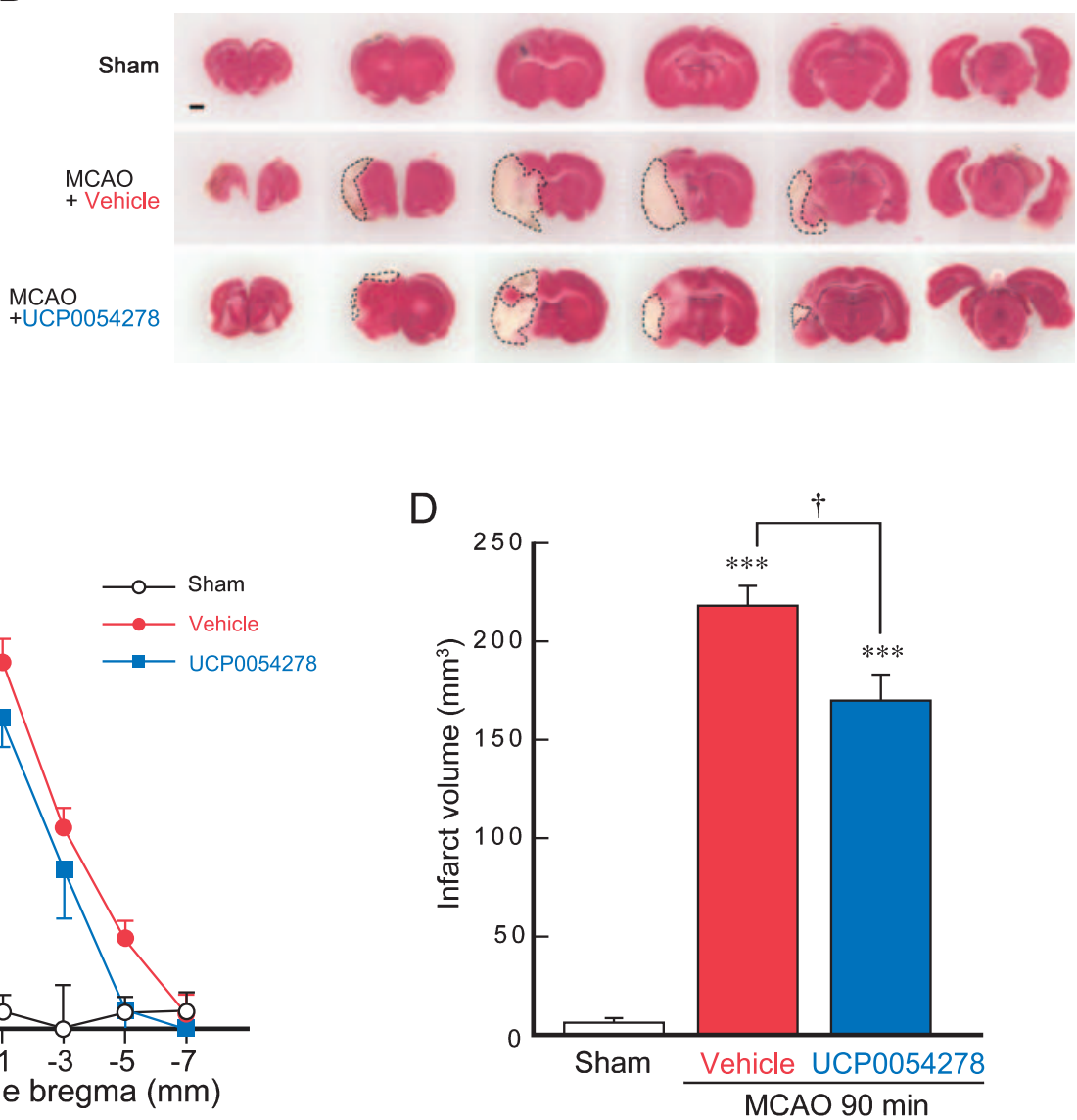

Fig. 1. DJ-1 modulator UCP0054278 reduces infarct size after focal cerebral ischemia and reperfusion. A: Chemical structure of UCP0054278. B: Representative photographs showing coronal brain sections, from the left, at $+5,+3,+1,-1,-3$, and $-5 \mathrm{~mm}$ anterior-posterior from the bregma with TTC staining at 1 day after MCAO in sham-operated rats $(\mathrm{n}=5)$ and MCAO-ischemic rats injected with sterilized physiological saline in the presence of the vehicle $(1 \%$ DMSO, $\mathrm{n}=5)$ or UCP0054278 $(4 \mathrm{nmol} / 4 \mu \mathrm{L}$, $\mathrm{n}=5$ ), at $30 \mathrm{~min}$ before MCAO. Scale bar: $1 \mathrm{~mm}$. C and D: Quantitative analysis of infarct area and volume. Data are each the mean \pm S.E.M. Significance (Bonferroni/Dunn post hoc comparisons after ANOVA): $* * *<0.001$ vs. sham-operated rats; ${ }^{\dagger} P<0.05$ vs. vehicle-injected rats.

pentobarbital, $50 \mathrm{mg} / \mathrm{kg}$, i.p.), rats received a microinjection of UCP0054278 $(4 \mathrm{nmol} / 4 \mu \mathrm{L})$ in the left striatum (coordinates: $1 \mathrm{~mm}$ anterior, $4 \mathrm{~mm}$ left lateral, and $5 \mathrm{~mm}$ ventral from the bregma). Sterilized physiological saline containing 1\% dimethyl sulfoxide (DMSO) was used as the vehicle control in a final volume of $4 \mu \mathrm{L}$. After $30 \mathrm{~min}$, left middle cerebral artery occlusion (MCAO) for $90 \mathrm{~min}$ and reperfusion were performed as described previously (6). All animal experiments were carried out in accordance with the National Institutes of Health Guide for the Care and Use of Laboratory Animals, and the protocols were approved by the Committee for Animal Research at Kyoto Pharmaceutical University. At $24 \mathrm{~h}$ after MCAO, 2-mm-thick coronal sections of rat brains were stained by 2,3,5-triphenyltetrazolium chloride (TTC; Wako Pure Chemical Industries, Osaka), and infarct areas and volumes were quantified.
Using human neuroblastoma SH-SY5Y cells, we established a DJ-1-knockdown cell line (6). Normal and DJ-1-knockdown SH-SY5Y cells were treated with various concentrations of hydrogen peroxide $\left(\mathrm{H}_{2} \mathrm{O}_{2}\right)$ in the presence of vehicle $(0.01 \%$ DMSO $)$ or UCP0054278 (containing $0.01 \%$ DMSO) for $1 \mathrm{~h}$ (ROS production) or $24 \mathrm{~h}$ (cell survival). To detect $\mathrm{H}_{2} \mathrm{O}_{2}$-induced intracellular ROS production, we used a redox-sensitive dye, 5-(and -6)-chloromethyl-2',7'-dichlorodihydrofluorescein diacetate acetyl ester $\left(\mathrm{CM}-\mathrm{H}_{2} \mathrm{DCFDA}\right.$; Invitrogen, Carlsbad, CA, USA), and scanned the fluorescence intensity of oxidized DCF under a confocal microscope (LSM510 META; Carl Zeiss, Jena, Germany). Subsequently, we assessed cell viability using 3-(4,5-dimethyl-2-thiazolyl)2,5-diphenyltetrazolium bromide (MTT; Dojindo Laboratories, Kumamoto).

In vitro formation of hydroxyl radical $\left({ }^{\circ} \mathrm{OH}\right)$ was monitored by electron spin resonance (ESR) spectro- 
metry with 5,5-dimethyl-1-pyrroline- $N$-oxide (DMPO; Labotec, Tokyo) according to the previously described method (9). Vehicle (0.01\% DMSO) or UCP0054278 (including $0.01 \% \mathrm{DMSO}$ ) was added to the reaction mixture (total volume $200 \mu \mathrm{L}$ ) in $100 \mathrm{mM}$ phosphate buffer containing $25 \mu \mathrm{M}$ diethylene-triamine pentaacetic acid, $25 \mu \mathrm{M} \mathrm{FeSO}$, $100 \mu \mathrm{M} \mathrm{H}_{2} \mathrm{O}_{2}$, and $112.5 \mathrm{mM}$ DMPO

Results are presented as the mean \pm S.E.M. The significance of differences was determined by an analysis of variance (ANOVA). Further post hoc comparisons were performed using Bonferroni/Dunn tests (Stat View; Abacus Concepts, Berkeley, CA, USA).

We have previously found that MCAO-induced neuronal death was significantly inhibited by recombinant DJ-1 protein, which was injected before the reperfusion, but the injection after reperfusion did not change the amount of cell death; and that simultaneous addition of DJ-1 protein inhibited $\mathrm{H}_{2} \mathrm{O}_{2}$-induced ROS production and cell death in SH-SY5Y cells (6). Preliminarily, when we injected UCP0054278 after reperfusion, the infarct volume did not change (data not shown). On the other hand, we took into account drug diffusion in the striatum and uptake into neuronal cells. Because neurons, glial cells, and vessels are three-dimensionally and very tightly connected and the extracellular space is very narrow in the brain parenchyma, diffusion and neuronal uptake of drug may be delayed and be later than those in the in vitro culture. Based on these observations, we performed an intrastriatal microinjection of UCP0054278 at $30 \mathrm{~min}$ before the onset of MCAO in this study. At $24 \mathrm{~h}$ after MCAO, although a marked regional loss of TTC staining occurred in the ipsilateral cerebral cortex and striatum in vehicleinjected rats, the area of TTC staining lost was smaller with the microinjection of UCP0054278 (Fig. 1B). In the quantitative analysis, each infarct area was relatively smaller and the total infarct volume was significantly reduced by the administration of the DJ- 1 modulator UCP0054278 compared with that in vehicle-injected rats (Fig. 1: C and D).

In normal human SH-SY5Y cells, $\mathrm{H}_{2} \mathrm{O}_{2}$ caused cell death after $24 \mathrm{~h}$ in a concentration-dependent manner (Fig. 2B). This cell death was significantly inhibited by simultaneous treatment with $10 \mu \mathrm{M}$ UCP0054278. In DJ-1-knockdown SH-SY5Y cells, the expression of endogenous DJ-1 protein was suppressed by approximately $77 \%$, and massive $\mathrm{H}_{2} \mathrm{O}_{2}$-induced cell death occurred (Fig. 2: A and C). Interestingly, UCP0054278 did not protect against $\mathrm{H}_{2} \mathrm{O}_{2}$-induced cell death in DJ-1knockdown cells.

In normal SH-SY5Y cells, incubation with $100 \mu \mathrm{M}$ $\mathrm{H}_{2} \mathrm{O}_{2}$ for $1 \mathrm{~h}$ induced marked intracellular ROS produc-
A
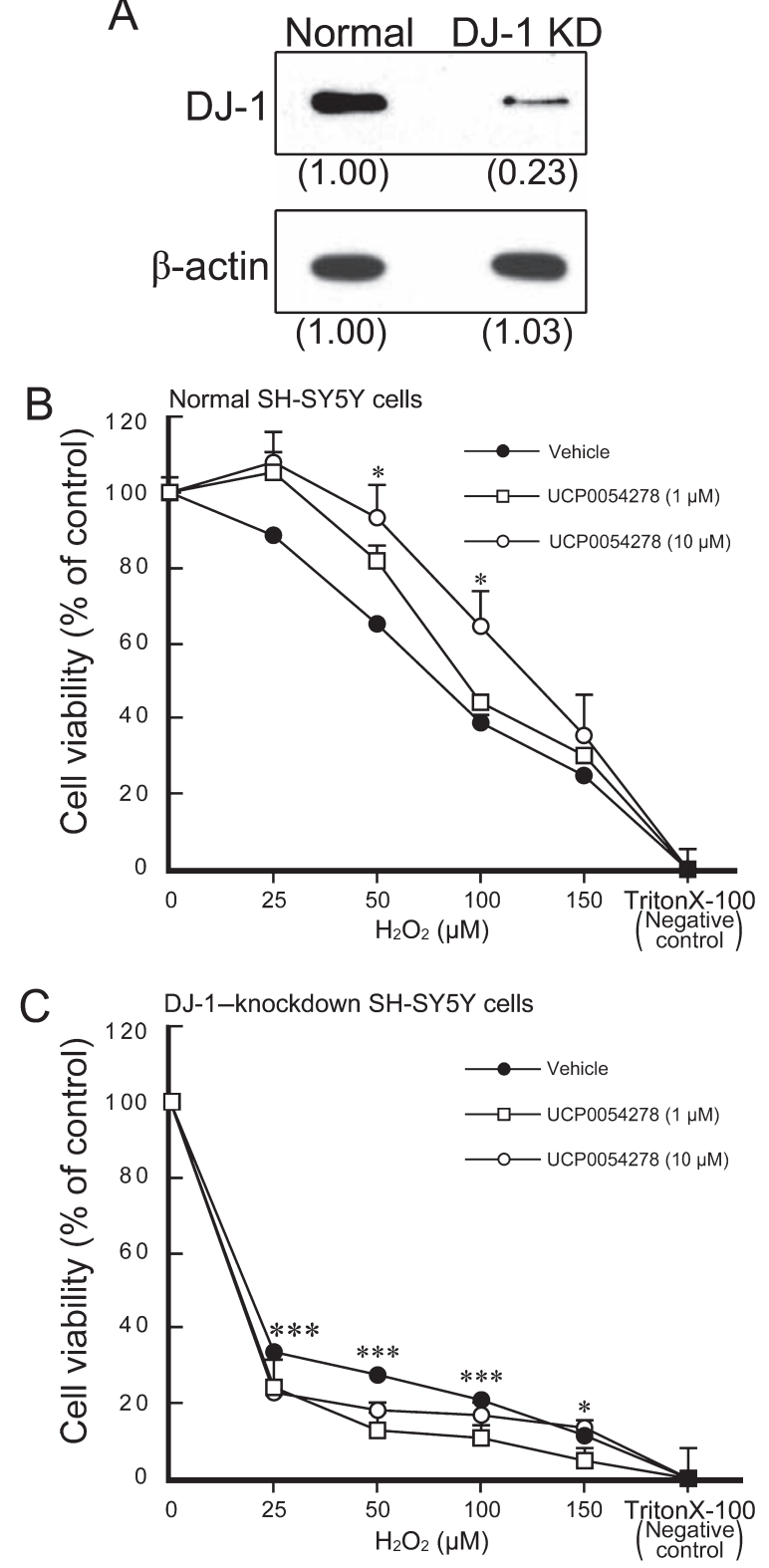

Fig. 2. Effects of UCP0054278 on hydrogen peroxide-induced cell death. A: Expression of endogenous DJ-1 protein. The intensity of the expression level in normal cells was set to 1.00. B and C: Normal and DJ-1-knockdown SH-SY5Y cells were treated with various concentrations of $\mathrm{H}_{2} \mathrm{O}_{2}$ in the presence of the vehicle $(0.01 \%$ DMSO) or UCP0054278 at 1 or $10 \mu \mathrm{M}$ for $24 \mathrm{~h}$, and cell viability was measured by an MTT assay. Data are each the mean \pm S.E.M. of three determinations. Significance (Bonferroni/Dunn post hoc comparisons after ANOVA): ${ }^{*} P<0.05, * * * P<0.001$ vs. Vehicle in normal $\mathrm{SH}-$ SY5Y cells shown in panel B.

tion (Fig. 3A), while this was only slightly induced by $50 \mu \mathrm{M} \mathrm{H}_{2} \mathrm{O}_{2}$ (Fig. 3B). In DJ-1-knockdown cells, even $50 \mu \mathrm{M} \mathrm{H}_{2} \mathrm{O}_{2}$ induced significant fluorescence intensity after $1 \mathrm{~h}$ (Fig. 3B). On the other hand, simultaneous treatment with $10 \mu \mathrm{M}$ UCP0054278 significantly inhibited ROS production, which had been induced by 
A
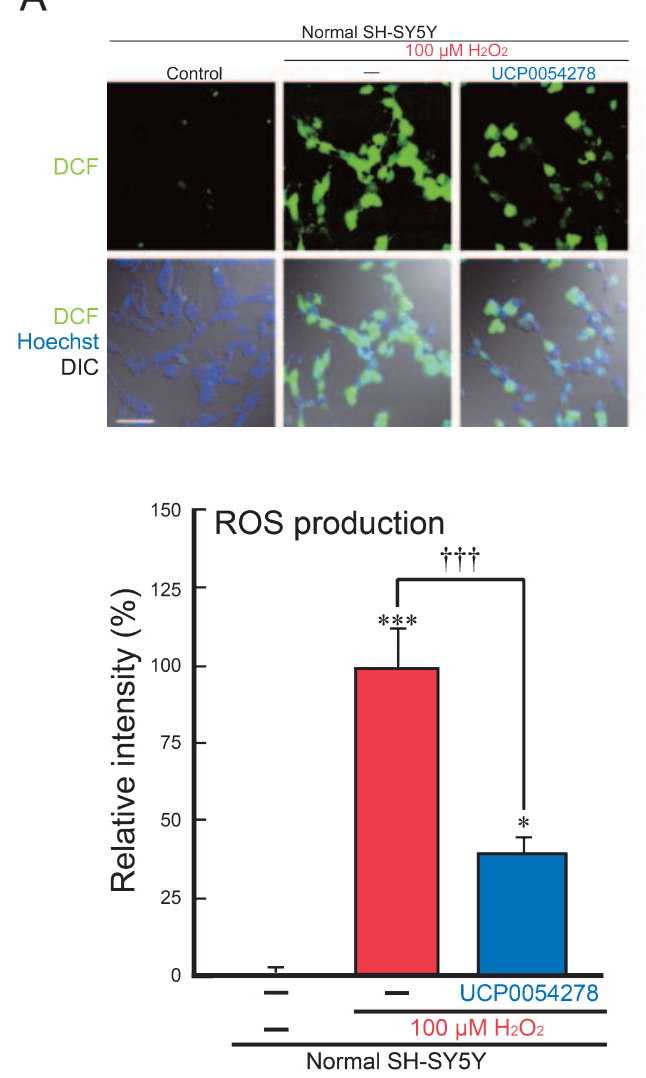

C<smiles>CN(N)C(=O)O</smiles>

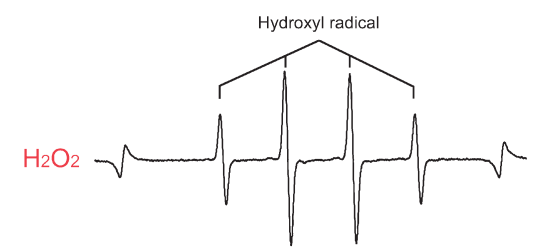

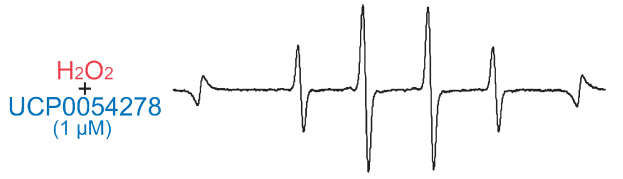

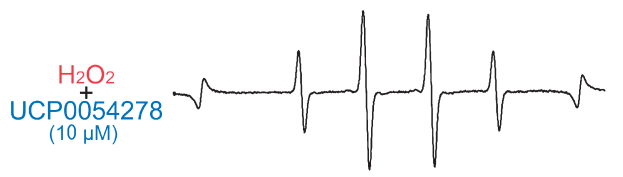

B

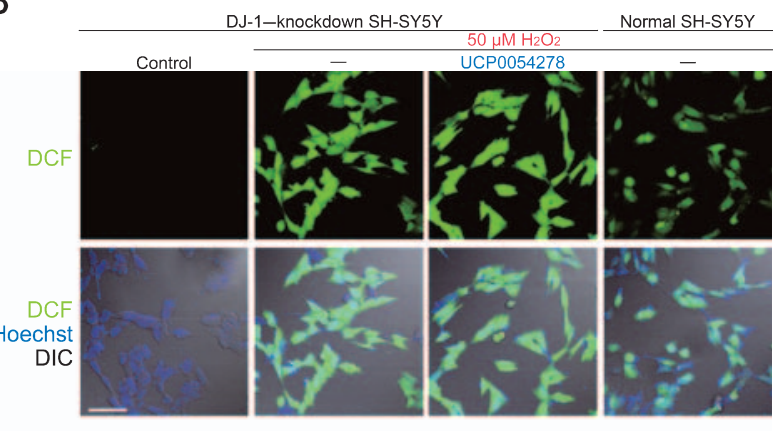

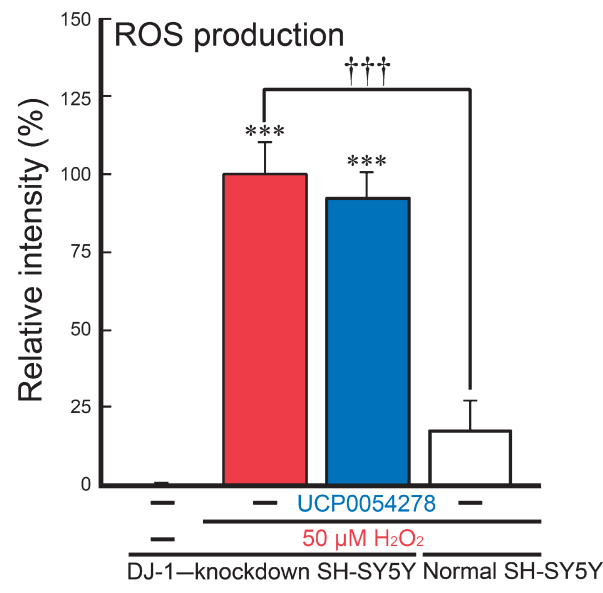

D

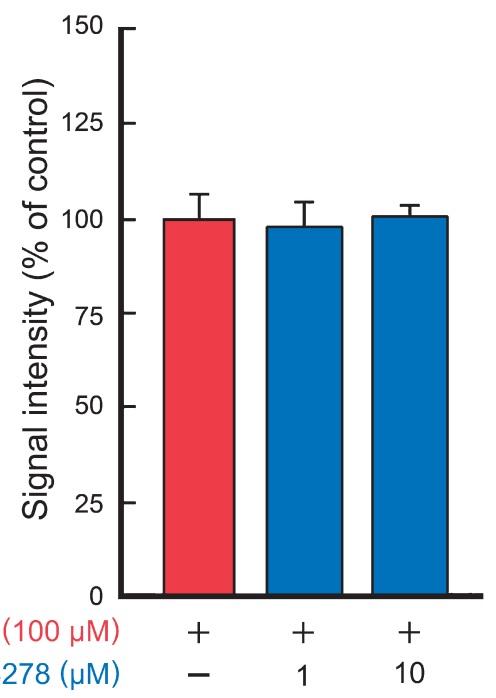

Fig. 3. Effect of UCP0054278 on $\mathrm{H}_{2} \mathrm{O}_{2}$-induced ROS production. Normal and DJ-1-knockdown SH-SY5Y cells were treated with $\mathrm{H}_{2} \mathrm{O}_{2}$ in the presence of vehicle $\left(0.01 \%\right.$ DMSO) or $10 \mu \mathrm{M} \mathrm{UCP} 0054278$ for $1 \mathrm{~h}$. Subsequently, CM- $\mathrm{H}_{2}$ DCFDA was added, and the fluorescence intensity of oxidized DCF (green) was then visualized and measured by a confocal microscope. Nuclei were stained with Hoechst 33258 (blue) and cellular images (cell shapes) were obtained by the difference interference contrast (DIC). A: Treatment with $100 \mu \mathrm{M} \mathrm{H}_{2} \mathrm{O}_{2}$ for $1 \mathrm{~h}$. B: Treatment with $50 \mu \mathrm{M} \mathrm{H}_{2} \mathrm{O}_{2}$ for $1 \mathrm{~h}$. Data are each the mean \pm S.E.M. of three determinations, based on the intensity in cells treated with $\mathrm{H}_{2} \mathrm{O}_{2}$ alone as $100 \%$. Significance (Bonferroni/Dunn post hoc comparisons after ANOVA): ${ }^{*} P<0.05, * * * P<0.001$ vs. Vehicle; ${ }^{\Uparrow} P<0.001$ vs. $\mathrm{H}_{2} \mathrm{O}_{2}$ alone. Scale bar: $50 \mu$ m (Vehicle in A and B). $\mathrm{C}$ and D: ESR analysis. ESR signals of DMPO-OH spin adducts in control, $\mathrm{H}_{2} \mathrm{O}_{2}$ with $\mathrm{Fe}^{2+}$, or UCP0054278 (containing $0.01 \%$ DMSO). $\mathrm{Mn}^{2+}$ signal was used as an internal reference (both edges in $\mathrm{C}$ ). Quantitative measurement of ${ }^{\circ} \mathrm{OH}$ generation from $100 \mu \mathrm{M} \mathrm{H}_{2} \mathrm{O}_{2}$ is shown in panel D. Each value is the mean \pm S.E.M. of three determinations, based on $\mathrm{H}_{2} \mathrm{O}_{2}$ alone as $100 \%$. 
$100 \mu \mathrm{M} \mathrm{H}_{2} \mathrm{O}_{2}$, in normal SH-SY5Y cells (Fig. 3A). Unfortunately, in DJ-1-knockdown cells, this DJ-1 modulator lost its inhibitory effect on ROS production induced by $50 \mu \mathrm{M} \mathrm{H}_{2} \mathrm{O}_{2}$ (Fig. 3B). Although inhibitory effects of UCP0054278 were different extents on $\mathrm{H}_{2} \mathrm{O}_{2}$ induced ROS production and cell death, this may be caused by the different treatment time, that is, one and $24 \mathrm{~h}$, respectively.

We further examined whether UCP0054278 can directly scavenge ${ }^{\circ} \mathrm{OH}$ by ESR analysis using the spin trapper DMPO. As an internal reference, the $\mathrm{Mn}^{2+}$ signal was detected as two peaks at both edges (Fig. 3C). In the presence of $100 \mu \mathrm{M} \mathrm{H}_{2} \mathrm{O}_{2}$, four major peaks with an intensity ratio of 1:2:2:1 appeared at the mid-section between the $\mathrm{Mn}^{2+}$ signal. A quartet signal indicates the DMPO-OH spin adduct (9). However, $\mathrm{H}_{2} \mathrm{O}_{2}$-induced DMPO-OH signal could not be reduced by UCP0054278 at either 1 or $10 \mu \mathrm{M}$ (Fig. 3C).

Although oxygen is necessary for life, it paradoxically generates ROS, which is highly toxic to cells, as a byproduct of its metabolism. In addition, ROS is massively produced in the brain after cerebral ischemia and reperfusion. Oxidative stress can be defined as an imbalance between ROS generation and the antioxidant capacity of a cell. Recent studies, together with our experiments, indicate that DJ-1 may sense oxidative stress. In brief, we previously found that treatment with recombinant human DJ-1 protein protected against nigral and striatal neuronal cell death in 6-hydroxydopamine-induced PD model rats and MCAO-ischemic rats $(4,6)$. It is known that protein oxidation means a trapping of oxygen atoms (Os) into amino acid residues, that is, methionine and cysteine that are oxidized to Met-SO (1O) and Cys- $\mathrm{SO}_{3} \mathrm{H}$ (3Os), respectively; and that rat and human DJ-1 protein has four methionine and three cysteine residues (10). Therefore, if these amino acid residues are fully oxidized, one molecule of DJ-1 protein has a potential total of additional 13Os. On the other hand, oxidation at C106 is necessary for DJ-1 to exert an antioxidant response, and massive oxidation may cause a loss-of-function of DJ-1 $(3,10)$. Thus, $\mathrm{SOH}-$ and $\mathrm{SO}_{2} \mathrm{H}$-oxidation at $\mathrm{C} 106$ may produce the active forms (as oxidative stress sensor), while $\mathrm{SO}_{3} \mathrm{H}-$ peroxidation caused loss-of-function and produced the inactive form. By in silico virtual screening, we recently found UCP0054278 as a DJ-1 modulator that can bind to the $\mathrm{SO}_{2} \mathrm{H}$-oxidized $\mathrm{C} 106$ region. In addition, direct binding between UCP0054278 and recombinant wildtype of DJ-1 protein (but not C106S-mutated DJ-1, bovine serum albumin, or glutathione- $S$-transferase) was detected by a biosensor chip of the quartz crystal microbalance system (8), suggesting that UCP0054278 binding is relatively specific to wild-type of DJ-1 protein and its binding site may be the $\mathrm{C} 106$ region. Furthermore, $\mathrm{H}_{2} \mathrm{O}_{2}$-induced formation of hyperoxidative C106$\mathrm{SO}_{3} \mathrm{H}$ was inhibited by UCP0054278 (8). On the other hand, DJ-1 is relatively rich in neurons and glial cells, except for nigral dopaminergic neurons (5). In addition to the presence of DJ-1 in the cytoplasm, mitochondria, and nucleus, recent studies reported that DJ-1 protein was detected in extracellular spaces such as plasma and cerebrospinal fluids $(11,12)$, suggesting that DJ-1 protein may function in both intracellular and extracellular spaces. Therefore, we consider that amount of endogenous DJ-1 protein is sufficient for UCP0054278 function in both in vivo rat brain and in vitro normal SH-SY5Y cells.

In the present study, we revealed that the intrastriatal pre-injection of UCP0054278 inhibited neurodegeneration induced by MCAO and reperfusion in rats. In normal SH-SY5Y cells, simultaneous treatment of UCP0054278 reduced ROS production and cell death induced by $100 \mu \mathrm{M} \mathrm{H}_{2} \mathrm{O}_{2}$. In DJ-1-knockdown cells, $\mathrm{H}_{2} \mathrm{O}_{2}$ at an even lower concentration $(50 \mu \mathrm{M})$ significantly induced ROS production and cell death. However, DJ-1 knockdown caused the loss of UCP0054278induced inhibitory effects toward either ROS production or cell death. In addition, UCP0054278 itself could not directly scavenge $\mathrm{OH}$. These results indicate that endogenous DJ-1 protein is necessary for the antioxidant and neuroprotective effects induced by UCP0054278. In brief, UCP0054278 binds to DJ-1 protein as the stimulatory modulator. Furthermore, since UCP0054278 binds to the $\mathrm{SO}_{2} \mathrm{H}$-oxidized $\mathrm{C} 106$ region in wild-type DJ-1 protein, it is possible that UCP0054278 stabilizes active DJ-1 with $\mathrm{SO}_{2} \mathrm{H}$-oxidized $\mathrm{C} 106$ and/or inhibits peroxidation to inactive DJ-1 with $\mathrm{SO}_{3} \mathrm{H}$-oxidized C106.

In addition, DJ-1 induces indirect antioxidant episodes, which are mediated through the stabilizing nuclear factor erythroid 2-related factor (Nrf2) by preventing association of the Kelch-like erythroid cell-derived protein with cap'n'collar homology (ECH)-associated protein-1 (Keap1), resulting in activation of antioxidant transcriptional responses such as induction and enhanced expression of $\mathrm{NAD}(\mathrm{P}) \mathrm{H}$ quinine oxidoreductase-1 (NQO1), heme oxigenase-1, superoxide dismutase-1, thioredoxin, and so on (13).

On the other hand, recent studies have reported that DJ-1 inhibits several apoptotic pathways such as the pyrimidine tract-binding protein-associated splicing factor (PSF)/54-kDa nuclear RNA-binding protein (p54nrb) pathway (14) and/or apoptosis signal regulating kinase 1 (ASK1) / homeodomain-interacting protein kinase (HIPK1)/ death-domain-associated protein (Daxx) pathway $(15,16)$. Thus, DJ-1 protein may induce: i) an immediate antioxidant response by direct 
trapping of oxygen atoms into the amino acids; ii) early indirect antioxidant responses probably by Nrf2mediated induction of antioxidant enzymes/molecules; and iii) delayed anti-apoptotic responses. Based on these observations, we consider that UCP0054278 may maintain and enhance DJ-1-induced anti-oxidative and anti-apoptotic activation and that these responses may synergistically act to prevent both ROS production and neuronal cell death. Therefore, the interaction of $10 \mu \mathrm{M}$ UCP0054278 with endogenous DJ-1 could inhibit $100 \mu \mathrm{M} \mathrm{H}_{2} \mathrm{O}_{2}$-induced ROS production and cell death in the in vitro culture model. These studies raise the possibility that UCP0054278 is a new type of neuroprotective drug for the treatment of brain ischemia.

In conclusion, this is the first report to show that UCP0054278 has a neuroprotective effect in an in vivo brain ischemia animal model. UCP0054278 may bind to the $\mathrm{SO}_{2} \mathrm{H}$-oxidized $\mathrm{C} 106$ region in endogenous DJ-1 protein and then maintain DJ-1-induced anti-oxidative and anti-apoptotic responses. The present results suggest that DJ-1 stimulatory modulators, such as UCP0054278, may be useful for neuroprotective treatment in cytoprotective therapy for various oxidative stress-mediated disorders.

\section{Acknowledgments}

This study was supported in part by Open Research Programs from the Ministry of Education, Culture, Sports, Science, and Technology (MEXT) and by the Program for Promotion of Fundamental Studies in Health Sciences of the National Institute of Biomedical Innovation (NIBIO) in Japan.

\section{References}

1 Nagakubo D, Taira T, Kitaura H, Ikeda M, Tamai K, IguchiAriga SM, et al. DJ-1, a novel oncogene which transforms mouse NIH3T3 cells in cooperation with ras. Biochem Biophys Res Commun. 1997;31:509-513.

2 Bonifati V, Rizzu P, van Baren MJ, Schaap O, Breedveld GJ, Krieger E, et al. Mutations in the DJ-1 gene associated with autosomal recessive early-onset parkinsonism. Science. 2003; 299:256-259.

3 Taira T, Saito Y, Niki T, Iguchi-Ariga SM, Takahashi K, Ariga H. DJ-1 has a role in antioxidative stress to prevent cell death. EMBO Rep. 2004;5:213-218.

4 Inden M, Taira T, Kitamura Y, Yanagida T, Tsuchiya D, Takata
K, et al. PARK7 DJ-1 protects against degeneration of nigral dopaminergic neurons in Parkinson's disease rat model. Neurobiol Dis. 2006;24:144-158.

5 Yanagida T, Takata K, Inden M, Kitamura Y, Taniguchi T, Yoshimoto K, et al. Distribution of DJ-1, Parkinson's diseaserelated protein PARK7, and its alteration in 6-hydroxydopamine-treated hemiparkinsonian rat brain. J Pharmacol Sci. 2006;102:243-247.

6 Yanagisawa D, Kitamura Y, Inden M, Takata K, Taniguchi T, Morikawa S, et al. DJ-1 protects against neurodegeneration caused by focal cerebral ischemia and reperfusion in rats. $\mathrm{J}$ Cereb Blood Flow Metab. 2008;28:563-578.

7 Kinumi T, Kimata J, Taira T, Ariga H, Niki E. Cysteine-106 of DJ-1 is the most sensitive cysteine residue to hydrogen peroxidemediated oxidation in vivo in human umbilical vein endothelial cells. Biochem Biophys Res Commun. 2004;317:722-728.

8 Miyazaki S, Yanagida T, Nunome K, Ishikawa S, Inden M, Kitamura $\mathrm{Y}$, et al. DJ-1-binding compounds prevent oxidative stress-induced cell death and movement defect in Parkinson's disease model rats. J Neurochem. 2008;105:2418-2434.

9 Yanagida T, Takeuchi H, Kitamura Y, Takata K, Minamino H, Shibaike T, et al. Synergistic effect of galantamine on nicotineinduced neuroprotection in hemiparkinsonian rat model. Neurosci Res. 2008;62:254-261.

10 Zhou W, Zhu M, Wilson MA, Petsko GA, Fink AL. The oxidation state of DJ-1 regulates its chaperone activity toward alpha-synuclein. J Mol Biol. 2006;356:1036-1048.

11 Allard L, Burkhard PR, Lescuyer P, Burgess JA, Walter N, Hochstrasser DF, et al. PARK7 and nucleoside diphosphate kinase A as plasma markers for the early diagnosis of stroke. Clin Chem. 2005;51:2043-2051.

12 Waragai M, Wei J, Fujita M, Nakai M, Ho G, Masliah E, et al. Increased level of DJ-1 in the cerebrospinal fluids of sporadic Parkinson's disease. Biochem Biophys Res Commun. 2006;345: 967-972.

13 Clements CM, McNally RS, Conti BJ, Mak TW, Ting JP. DJ-1, a cancer-and Parkinson's disease-associated protein, stabilizes the antioxidant transcriptional master regulator Nrf2. Proc Natl Acad Sci U S A. 2006;103:15091-15096.

14 Xu J, Zhong N, Wang H, Elias JE, Kim CY, Woldman I, et al. The Parkinson's disease-associated DJ-1 protein is a transcriptional co-activator that protects against neuronal apoptosis. Hum Mol Genet. 2005;14:1231-1241.

15 Junn E, Taniguchi H, Jeong BS, Zhao X, Ichijo H, Mouradian MM. Interaction of DJ-1 with Daxx inhibits apoptosis signalregulating kinase 1 activity and cell death. Proc Natl Acad Sci U S A. 2005;102:9691-9696.

16 Sekito A, Koide-Yoshida S, Niki T, Taira T, Iguchi-Ariga SM, Ariga H. DJ-1 interacts with HIPK1 and affects $\mathrm{H}_{2} \mathrm{O}_{2}$-induced cell death. Free Radic Res. 2006;40:155-165. 